\title{
Preconceptional folic acid supplement use in Lebanon
}

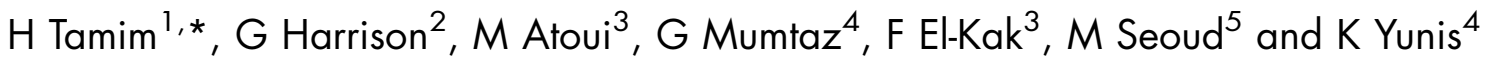 \\ for the National Collaborative Perinatal Neonatal Network (NCPNN) \\ ${ }^{1}$ School of Kinesiology \& Health Sciences, York University, Bethune College, 4700 Keele Street, Toronto, \\ Ontario, Canada, M3J 1P3: ${ }^{2}$ School of Public Health, University of California, Los Angeles, CA, USA: \\ ${ }^{3}$ Department of Health Behavior \& Education, American University of Beirut, Beirut, Lebanon: ${ }^{4}$ Department of \\ Pediatrics, American University of Beirut, Beirut, Lebanon: ${ }^{5}$ Department of Obstetrics \& Gynecology, American \\ University of Beirut, Beirut, Lebanon
}

\section{Submitted 3 October 2007: Accepted 3 April 2008: First published online 11 July 2008}

\begin{abstract}
Objective: The objective of the present study was to assess the prevalence and determinants of preconceptional folic acid supplement use among pregnant women in Lebanon.

Design/setting/subjects: The study was a descriptive epidemiological study. Analysis was performed on 5280 deliveries admitted to twelve member hospitals of the National Collaborative Perinatal Neonatal Network during the period September 2003-January 2005. Information on folic acid intake and maternal and neonatal characteristics were obtained from obstetric charts along with direct interviews performed by trained personnel. Logistic regression was performed to determine the predictors of preconceptional folic acid use.

Results: The overall use of preconceptional folic acid supplementation was $14 \cdot 0 \%$ (18.6\% in urban hospitals $v .2 \cdot 7 \%$ in rural hospitals). Higher socio-economic status, lower parity and having a history of previous spontaneous abortions were significantly associated with preconceptional folic acid use.

Conclusion: Our study shows that Lebanon currently has a low rate of preconceptional folic acid supplement use. Intervention through the means of awareness campaigns needs to be implemented on a national level.
\end{abstract}

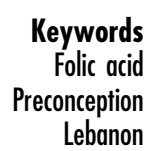

Keywords reconception Lebanon
Congenital anomalies affect an estimated 3\% of newborns worldwide. In the early 1990s, it ranked tenth on the list of disability-adjusted life years lost in the Global Burden of Disease Study ${ }^{(1)}$. Nearly 50 years ago, it was found that the B-vitamin folic acid plays a role in promoting normal embryonic development ${ }^{(2)}$. It was advised as a general guideline that all females of childbearing age take a supplement of $0.4 \mathrm{mg}$ folic acid to reduce the risk of congenital malformations, including neural tube defects (NTD) ${ }^{(3)}$. Periconceptional supplementation with folic acid (before conception and during the first 12 weeks of pregnancy) was found to decrease the risk of NTD by $50-70 \%$, while also protecting from other birth defects such as those of the heart, limbs, urinary tract, cleft lip and palate, as well as other major structural abnormalities ${ }^{(4,5)}$.

The 1990s and early 2000s witnessed an increase in the worldwide use of periconceptional folic acid supplementation as many developed countries promoted awareness campaigns on the importance of folic acid. Increases in the prevalence of periconceptional folic acid use were seen: from $27 \%$ to $48 \%$ in the $\mathrm{UK}^{(6)}$, from $5 \%$ to $36 \%$ in The Netherlands $^{(6)}$, from $14 \%$ to $83 \%$ in Ireland ${ }^{(7)}$, from $19 \%$ to $43 \%$ in Western Australia ${ }^{(8)}$, from $32 \%$ to $40 \%$ in the USA ${ }^{(3)}$ and from $17 \%$ to $28 \%$ in Canada ${ }^{(9)}$. Although these improvements are notable, a large portion of pregnancies remain unprotected. For the latter reason, folic acid fortification of staple foods (flour, breakfast cereals, etc.) has begun in many countries such as Canada ${ }^{(9)}$, Australia ${ }^{(10)}$, Germany $^{(11)}$, Chile ${ }^{(12)}$, Costa Rica ${ }^{(13)}$ and the USA ${ }^{(14)}$. A $26 \%$ reduction in NTD prevalence has been reported in the USA since mandatory fortification ${ }^{(14)}$. On the other hand, researchers in other countries like Japan and Finland have recently identified a possible need for intervention because dietary folic acid intake is suspected to be inadequate there ${ }^{(15,16)}$.

Several studies have explored socio-economic correlates of periconceptional folic acid use. Greater probability of supplement use has been associated with higher socio-economic status, first pregnancies, maternal age greater than 30 years, married status and non-smoking ${ }^{(17)}$. A recent study done in The Netherlands found that, especially among women with a low level of education, a diet low in folic acid was associated with increased risk of giving birth to a child with a congenital heart defect ${ }^{(18)}$.

In the Middle East region, there are very few data available on preconceptional and periconceptional use of 
folic acid. A study done in Israel following a national awareness campaign showed that preconceptional folic acid use was $5 \cdot 2 \%$ before the campaign, increasing to $30.5 \%$ after the intervention ${ }^{(19)}$. Positive associations were found between folic acid utilization, increasing years of education and older age ${ }^{(19)}$. Using a small and selective sample, a study carried out in the United Arab Emirates (UAE) found the prevalence of periconceptional folic acid use to be $45 \%$ and associated with higher education and being of non-UAE nationality ${ }^{(20)}$.

In Lebanon, there is no national policy about folic acid fortification or supplement intake; the practice is left to the individual physician's judgement. Furthermore, no studies have yet been done to determine the prevalence of preconceptional folic acid use. Such a study is a mandatory step for an intervention awareness programme if one is to be implemented. The objective of the present study was to assess the prevalence and determine the predictors of preconceptional folic acid use among pregnant women in Lebanon.

\section{Methods}

The National Collaborative Perinatal Neonatal Network (NCPNN), established in 1998, is a voluntary collaborative network of professionals from different health-care institutions in Lebanon aiming to improve the health of pregnant women and their newborns through quality scientific research. The NCPNN has formed an integrated perinatal neonatal database covering deliveries at major hospitals throughout Lebanon. These hospitals are believed to be representative of Lebanese hospital deliveries but not of home deliveries, which are relatively low in prevalence $(12 \%)^{(21)}$. Data for the NCPNN database are collected and documented by trained nurses, midwives and research assistants using standardized questionnaires, approved by the Institutional Research Board. The questionnaires include items that cover parental sociodemographic characteristics as well as maternal and newborn health characteristics.

During the period September 2003 to January 2005 and according to the Central Administration for Statistics (Lebanese government statistical base), there were 98766 births in Lebanon. During this period, the NCPNN was selecting a random sample of newborns admitted to the normal nursery at each hospital by selecting every consecutive fifth case. The present study was a descriptive epidemiologic study that considered all live-born newborns admitted to the normal nursery and selected by the NCPNN during this time period. The resulting sample size was 7384 delivered newborns.

The sources of data used for the present study were: (i) direct interviews with mothers conducted after delivery and before hospital discharge; and (ii) review of obstetric charts. Socio-economic variables considered for the present study included maternal and paternal education, monthly household income, mode of hospital payment, class of admission and hospital region. Maternal characteristics included were maternal age at marriage, first pregnancy and current delivery, parity, gravidity and smoking behaviour. Obstetric and neonatal complications were defined as past or present births with congenital malformations, previous spontaneous abortions, and pregnancy complication. Questions involving folic acid supplement use were incorporated in the NCPNN questionnaire over the study period and collected by direct interviews. The questions elicited information on regular folic acid intake before pregnancy, regular folic acid intake after pregnancy, folic acid intake with or without vitamin supplement, and folic acid subscriber (physician, pharmacist, self). No information was collected as to the specific timing at which folic acid was taken before pregnancy. The subjects were asked about the brand of folic acid supplements they took and the number of tablets. However, the majority (more than 75\%) of the subjects who did consume preconception folic acid had missing information on the brand and/or the number of tablets consumed; and hence information on dose is not reported in the study. For the sake of the present study a question asking whether the current pregnancy was planned was added to the original questionnaire six months after the study was initiated.

Odds ratios and 95\% confidence intervals were calculated to assess the relationship between preconceptional folic acid use and all socio-economic variables, maternal characteristics, and obstetric and neonatal complications. The OR and 95\% CI reported are based on a logistic regression model where the dependent variable was preconceptional folic acid supplement use and the independent variables were the above-mentioned socio-economic, maternal, obstetric and neonatal characteristics that were significant at the bivariate analysis (crude analysis).

\section{Results}

Of the 7348 women selected for the study, 5280 (71.9\%) had information on preconceptional folic acid intake and hence analysis was limited to this group. The average age at delivery of the 5280 women included was $29 \cdot 2$ (sD 5.6) years, with $1739(33.0 \%)$ of the women being primigravidae. A total of $3512(69 \cdot 8 \%)$ of the women had their pregnancies previously planned, out of the patients for whom such information was available. Among primigravidae, $83 \cdot 1 \%$ of the pregnancies were planned with the average length of time between marriage and first pregnancy being $1 \cdot 3$ (sD $1 \cdot 3$ ) years. Of the women delivering in the participating hospitals, $3753(71 \cdot 1 \%)$ delivered in urban $v .1527(28.9 \%)$ in rural hospitals.

The prevalence of preconceptional folic acid use was $14 \cdot 0 \%: 18 \cdot 6 \%$ for women delivering in urban hospitals 
and $2.7 \%$ for women delivering in rural setting hospitals. The frequency of women taking preconceptional folic acid in a multivitamin supplement was $4.3 \%$ ( $n$ 226), while $10 \cdot 0 \%$ ( $n$ 526) were taking folic acid as a separate supplement. Physicians were the primary prescribers, with $92 \cdot 3 \%$ of the women taking preconceptional folic acid having had it recommended by a physician.

Table 1 shows the relationship between different characteristics and folic acid supplement use preconceptionally at the bivariate level. Preconceptional folic acid intake was found to be positively associated with socio-economic characteristics, measured as maternal and paternal education, monthly household income, private health insurance as mode of payment, urban setting hospitals and first class admissions (all $P=0 \cdot 000$ ). Maternal characteristics positively associated with preconceptional folic acid intake included older maternal age at marriage, first and current delivery, lower parity levels, and not smoking during pregnancy (all $P=0 \cdot 000$ ). Complications during pregnancy $(P=0 \cdot 019)$ and history of previous spontaneous abortions $(P=0 \cdot 000)$ were also positively associated with preconceptional folic acid supplement use. Although women with a previous infant with congenital malformations had higher folic acid intake, the association did not reach statistical significance $(P=0 \cdot 234)$.

Results of the logistic regression model (Table 2) showed that mothers delivering in urban hospitals were more likely to use preconceptional folic acid than those delivering in rural hospitals $(P<0 \cdot 01)$. Higher monthly household income and higher education significantly predicted preconceptional folic acid use (all $P<0 \cdot 01$ ). Similarly, private mode of payment $(P=0.02)$ and higher class of admission $(P=0.03)$ were other socio-economic status indicators associated with improved folic acid intake. Lower parity was significantly associated with positive preconceptional folic acid use $(P=0.04)$ and mothers who had experienced previous spontaneous abortions had greater probability of having taken preconceptional folic acid $(P<0 \cdot 01)$.

\section{Discussion}

Although it has been widely advised that all women of childbearing age take $0.4 \mathrm{mg}$ folic acid daily at least one month prior to conception and throughout the first trimester of pregnancy to decrease the risk of congenital malformations including NTD ${ }^{(22-24)}$, prevalence of intake of preconceptional folic acid in Lebanon was found to be $14.0 \%$, with $18.6 \%$ prevalence in urban setting hospitals and $2.7 \%$ in rural setting hospitals, an issue that needs to be given prompt attention. Preconceptional folic acid intake was found to increase as socio-economic conditions improved. Furthermore, certain maternal characteristics and obstetric and neonatal complications were also found to be associated with preconceptional folic acid intake.

Preconceptional folic acid intake in Lebanon, in comparison with the current $48 \%$ in the $\mathrm{UK}^{(6)}, 36 \%$ in The Netherlands $^{(6)}, 83 \%$ in Ireland ${ }^{(7)}$ and $40 \%$ in the USA ${ }^{(3)}$, was found to be markedly low at $14 \%$. It is important to note, however, that these countries have targeted women of childbearing age through national health awareness programmes that have been implemented since the mid1990s. In other countries with minimal or no national awareness campaigns conducted thus far, such as France, Spain, Germany and Italy, prevalence of periconceptional folic acid intake ranges from $1 \%$ to $4.5 \%{ }^{(25)}$. The prevalence of periconceptional folic acid in the $\mathrm{UAE}^{(20)}$, a country with a somewhat similar culture to Lebanon, was found to be $45.5 \%$, yet the generalizability of that study is questionable owing to the convenience sample of hospitals selected and the small sample size ( $n 336$ ) of the participants included.

Similar to other studies ${ }^{(3,17,26)}$, the present study showed that socio-economic status, measured through several indicators such as household monthly income, maternal education, mode of payment and class of admission, was associated with preconceptional folic acid supplement use. This is probably due to more awareness of the importance of and accessibility to antenatal and inter-pregnancy care. Mothers delivering in urban setting hospitals were also found to be at higher odds of using preconceptional folic acid than those delivering in rural hospitals, similar to a study that concluded that underprivileged communities were less likely to use preconceptional folic acid than their counterparts ${ }^{(22)}$. A possible explanation is more active continuing education on the part of physicians participating in hospitals in urban settings. A study done in Thailand, however, found that the media was an important source of information on the importance of folic acid $^{(23)}$. Primiparity was positively associated with preconceptional folic acid use, as found elsewhere in the literature ${ }^{(20)}$.

Similar to other studies, a significant association was noted between preconceptional folic acid intake and a history of spontaneous abortions ${ }^{(27)}$. One possible explanation is that mothers with previous complications had received folic acid as part of postpartum care to decrease the risk of complications in future or current pregnancies.

A limitation faced by the majority of such descriptive epidemiological studies is the possibility of recall bias occurring in respect to timing of folic acid tablet intake, especially as it is dependent on determining the onset of pregnancy ${ }^{(6)}$. Another bias that might have influenced the present results is the mistaking of folic acid for other multivitamin/mineral supplementation, such as iron tablets. However, most multivitamins sold in Lebanon, including iron tablets, contain the required amount of folic acid in their composition. On the other hand, the 
Table 1 Bivariate analysis characterizing preconceptional folic acid intake among Lebanese women, September 2003-January 2005

\begin{tabular}{|c|c|c|c|c|c|c|c|}
\hline & \multicolumn{6}{|c|}{ Folic acid before pregnancy } & \multirow[b]{3}{*}{$P$} \\
\hline & \multicolumn{2}{|c|}{ Total } & \multicolumn{2}{|c|}{ Yes } & \multirow[b]{2}{*}{ OR } & \multirow[b]{2}{*}{$95 \% \mathrm{Cl}$} & \\
\hline & $n$ & $\% *$ & $n$ & $\%+$ & & & \\
\hline \multicolumn{8}{|c|}{ Socio-economic characteristics } \\
\hline \multicolumn{8}{|c|}{ Maternal education } \\
\hline Illiterate/Elementary & 763 & $14 \cdot 8$ & 22 & $2 \cdot 9$ & $1 \cdot 0$ & Reference & \\
\hline Intermediate & 1045 & $20 \cdot 3$ & 59 & $5 \cdot 6$ & $2 \cdot 0$ & $1 \cdot 2,3 \cdot 3$ & \\
\hline Secondary/Technical & 1463 & $28 \cdot 4$ & 124 & $8 \cdot 5$ & $3 \cdot 1$ & $2 \cdot 0,5 \cdot 0$ & \\
\hline University & 1880 & $36 \cdot 5$ & 512 & $27 \cdot 2$ & $12 \cdot 6$ & $8 \cdot 2,19 \cdot 5$ & 0.000 \\
\hline \multicolumn{8}{|l|}{ Paternal education } \\
\hline Illiterate/Elementary & 940 & $18 \cdot 5$ & 28 & $3 \cdot 0$ & $1 \cdot 0$ & Reference & \\
\hline Intermediate & 989 & $19 \cdot 5$ & 56 & $5 \cdot 7$ & $2 \cdot 0$ & $1 \cdot 2,3 \cdot 1$ & \\
\hline Secondary/Technical & 1247 & $24 \cdot 6$ & 119 & $9 \cdot 5$ & $3 \cdot 4$ & $2 \cdot 3,5 \cdot 2$ & \\
\hline University & 1902 & $37 \cdot 5$ & 511 & $26 \cdot 9$ & $12 \cdot 0$ & $8 \cdot 1,17 \cdot 7$ & 0.000 \\
\hline \multicolumn{8}{|c|}{ Monthly household income (\$) } \\
\hline $300-499$ & 873 & $17 \cdot 4$ & 37 & $4 \cdot 2$ & $1 \cdot 0$ & Reference & \\
\hline $500-1499$ & 1626 & $32 \cdot 5$ & 147 & $9 \cdot 0$ & $2 \cdot 2$ & $1 \cdot 6,3 \cdot 3$ & \\
\hline 1500-2999 & 758 & $15 \cdot 1$ & 233 & $30 \cdot 7$ & $10 \cdot 0$ & $7 \cdot 0,14 \cdot 4$ & \\
\hline$>3000$ & 229 & $4 \cdot 6$ & 138 & $60 \cdot 3$ & $34 \cdot 3$ & $22 \cdot 5,52 \cdot 3$ & \\
\hline No information & 1522 & $30 \cdot 4$ & 144 & $9 \cdot 5$ & $2 \cdot 4$ & $1 \cdot 6,3 \cdot 4$ & 0.000 \\
\hline \multicolumn{8}{|l|}{ Hospital region } \\
\hline Urban & 3753 & $71 \cdot 1$ & 697 & $18 \cdot 6$ & $8 \cdot 3$ & $6 \cdot 0,11 \cdot 4$ & \\
\hline Rural & 1527 & $28 \cdot 9$ & 41 & $2 \cdot 7$ & $1 \cdot 0$ & Reference & 0.000 \\
\hline \multicolumn{8}{|l|}{ Mode of payment } \\
\hline Self & 436 & $9 \cdot 1$ & 48 & $10 \cdot 4$ & $1 \cdot 8$ & $1 \cdot 3,2 \cdot 6$ & \\
\hline Insurance company & 1799 & $35 \cdot 2$ & 487 & $27 \cdot 1$ & $5 \cdot 8$ & $4 \cdot 9,7 \cdot 0$ & \\
\hline Others & 2874 & $55 \cdot 7$ & 170 & $6 \cdot 0$ & $1 \cdot 0$ & Reference & 0.000 \\
\hline \multicolumn{8}{|l|}{ Class of admission } \\
\hline 1st & 1323 & $27 \cdot 4$ & 446 & $33 \cdot 7$ & $7 \cdot 5$ & $6 \cdot 1,9 \cdot 2$ & \\
\hline 2nd & 1421 & $29 \cdot 4$ & 133 & $9 \cdot 4$ & 1.5 & $1 \cdot 2,2 \cdot 0$ & \\
\hline 3rd & 2091 & $43 \cdot 2$ & 133 & $6 \cdot 4$ & $1 \cdot 0$ & Reference & 0.000 \\
\hline Maternal characteristics & & & & & & & \\
\hline Age at current delivery & & & & & & & \\
\hline$\leq 24$ years & 1170 & $22 \cdot 3$ & 68 & $5 \cdot 8$ & $1 \cdot 0$ & Reference & \\
\hline $25-29$ years & 1583 & $30 \cdot 2$ & 236 & $14 \cdot 9$ & $2 \cdot 8$ & $2 \cdot 1,3 \cdot 8$ & \\
\hline$\geq 30$ years & 2494 & $47 \cdot 5$ & 428 & $17 \cdot 2$ & $3 \cdot 4$ & $2 \cdot 6,4 \cdot 4$ & 0.000 \\
\hline Age at marriage & & & & & & & \\
\hline$\leq 24$ years & 2914 & $56 \cdot 0$ & 242 & $8 \cdot 3$ & $1 \cdot 0$ & Reference & \\
\hline $25-29$ years & 1545 & $29 \cdot 7$ & 313 & $20 \cdot 3$ & $2 \cdot 8$ & $2 \cdot 3,3 \cdot 4$ & \\
\hline$\geq 30$ years & 748 & $14 \cdot 4$ & 172 & $23 \cdot 0$ & $3 \cdot 3$ & $2 \cdot 7,4 \cdot 1$ & 0.000 \\
\hline Age at first pregnancy & & & & & & & \\
\hline$\leq 24$ years & 2411 & $48 \cdot 2$ & 154 & $6 \cdot 4$ & $1 \cdot 0$ & Reference & \\
\hline $25-29$ years & 1588 & $31 \cdot 7$ & 306 & $19 \cdot 3$ & $3 \cdot 5$ & $2 \cdot 8,4 \cdot 3$ & \\
\hline$\geq 30$ years & 1003 & $20 \cdot 1$ & 206 & $20 \cdot 5$ & $3 \cdot 8$ & $3 \cdot 0,4 \cdot 7$ & 0.000 \\
\hline Smoking during pregnar & & & & & & & \\
\hline No & 4664 & $89 \cdot 8$ & 686 & $14 \cdot 7$ & $2 \cdot 3$ & $1 \cdot 6,3 \cdot 2$ & \\
\hline Yes & 529 & $10 \cdot 2$ & 37 & $7 \cdot 0$ & $1 \cdot 0$ & Reference & 0.000 \\
\hline Gravidity & & & & & & & \\
\hline 1 & 1739 & $33 \cdot 0$ & 239 & $13 \cdot 7$ & $1 \cdot 0$ & $0 \cdot 8,1 \cdot 1$ & \\
\hline$\geq 2$ & 3527 & $67 \cdot 0$ & 498 & $14 \cdot 1$ & $1 \cdot 0$ & Reference & 0.736 \\
\hline Parity & & & & & & & \\
\hline 0 & 2063 & $39 \cdot 2$ & 338 & $16 \cdot 4$ & $3 \cdot 1$ & $2 \cdot 2,4 \cdot 4$ & \\
\hline $1-2$ & 2536 & $48 \cdot 2$ & 360 & $14 \cdot 2$ & $2 \cdot 7$ & $1 \cdot 9,3 \cdot 7$ & \\
\hline$\geq 3$ & 665 & $12 \cdot 6$ & 39 & $5 \cdot 9$ & $1 \cdot 0$ & Reference & 0.000 \\
\hline Obstetric and neonatal & & & & & & & \\
\hline Pregnancy complication & & & & & & & \\
\hline No & 3443 & $65 \cdot 7$ & 455 & $13 \cdot 2$ & $1 \cdot 0$ & Reference & \\
\hline Yes & 1801 & $34 \cdot 3$ & 281 & $15 \cdot 6$ & $1 \cdot 2$ & $1 \cdot 0,1 \cdot 4$ & 0.019 \\
\hline Previous spontaneous a & & & & & & & \\
\hline No & 3990 & $76 \cdot 7$ & 499 & $12 \cdot 5$ & $1 \cdot 0$ & Reference & \\
\hline Yes & 1213 & $23 \cdot 3$ & 232 & $19 \cdot 1$ & $1 \cdot 7$ & $1 \cdot 4,2 \cdot 0$ & 0.000 \\
\hline Previous infant with con & & & & & & & \\
\hline No & 5158 & $98 \cdot 6$ & 714 & $13 \cdot 8$ & $1 \cdot 0$ & Reference & \\
\hline Yes & 74 & $1 \cdot 4$ & 14 & $18 \cdot 9$ & 1.5 & $0 \cdot 8,2 \cdot 6$ & 0.234 \\
\hline
\end{tabular}

${ }^{*}$ Column percentage.

tRow percentage. 
Table 2 Regression model of preconceptional folic acid predictors among Lebanese women, September 2003-January 2005

\begin{tabular}{|c|c|c|c|}
\hline & OR & $95 \% \mathrm{Cl}$ & $P$ \\
\hline \multicolumn{4}{|l|}{ Socio-economic characteristics } \\
\hline Maternal education & & & $<0.01$ \\
\hline Illiterate/Elementary & $1 \cdot 0$ & Reference & \\
\hline Intermediate & $1 \cdot 3$ & $0.7,2.5$ & \\
\hline Secondary/Technical & $1 \cdot 2$ & $0 \cdot 7,2 \cdot 4$ & \\
\hline University & $2 \cdot 1$ & $1 \cdot 1,4 \cdot 0$ & \\
\hline \multicolumn{3}{|l|}{ Paternal education } & $0 \cdot 17$ \\
\hline Illiterate/Elementary & $1 \cdot 0$ & Reference & \\
\hline Intermediate & $1 \cdot 5$ & $0 \cdot 8,2 \cdot 7$ & \\
\hline Secondary/Technical & 1.9 & $1 \cdot 0,3 \cdot 4$ & \\
\hline University & $1 \cdot 6$ & $0.9,3.0$ & \\
\hline \multicolumn{3}{|l|}{ Monthly household income (\$) } & $<0.01$ \\
\hline $300-499$ & $1 \cdot 0$ & Reference & \\
\hline $500-1499$ & $1 \cdot 1$ & $0 \cdot 7,1 \cdot 8$ & \\
\hline $1500-2999$ & 1.9 & $1 \cdot 1,3 \cdot 3$ & \\
\hline$>3000$ & $6 \cdot 6$ & $3 \cdot 7,12 \cdot 0$ & \\
\hline No information & $1 \cdot 1$ & $0 \cdot 7,1 \cdot 8$ & \\
\hline \multicolumn{3}{|l|}{ Hospital region } & $<0.01$ \\
\hline Urban & $2 \cdot 7$ & $1 \cdot 7,4 \cdot 3$ & \\
\hline Rural & $1 \cdot 0$ & Reference & \\
\hline \multicolumn{3}{|l|}{ Mode of payment } & 0.02 \\
\hline Self & $1 \cdot 3$ & $0 \cdot 8,2 \cdot 0$ & \\
\hline Insurance company & $1 \cdot 6$ & $1 \cdot 2,2 \cdot 1$ & \\
\hline Others & $1 \cdot 0$ & Reference & \\
\hline \multicolumn{3}{|l|}{ Class of admission } & 0.03 \\
\hline $1 \mathrm{st}$ & $1 \cdot 7$ & $1 \cdot 1,2 \cdot 5$ & \\
\hline 2nd & $1 \cdot 2$ & $0.9,1 \cdot 7$ & \\
\hline $3 r d$ & $1 \cdot 0$ & Reference & \\
\hline \multicolumn{4}{|l|}{ Maternal characteristics } \\
\hline \multicolumn{3}{|l|}{ Age at current delivery } & 0.74 \\
\hline$\leq 24$ years & $1 \cdot 0$ & Reference & \\
\hline $25-29$ years & $1 \cdot 2$ & $0 \cdot 8,1 \cdot 8$ & \\
\hline$\geq 30$ years & $1 \cdot 2$ & $0 \cdot 7,2 \cdot 0$ & \\
\hline \multicolumn{3}{|l|}{ Age at marriage } & 0.49 \\
\hline$\leq 24$ years & $1 \cdot 0$ & Reference & \\
\hline $25-29$ years & $1 \cdot 0$ & $0 \cdot 7,1 \cdot 4$ & \\
\hline$\geq 30$ years & $1 \cdot 3$ & $0 \cdot 7,2 \cdot 1$ & \\
\hline \multicolumn{3}{|l|}{ Age at first pregnancy } & 0.08 \\
\hline$\leq 24$ years & $1 \cdot 0$ & Reference & \\
\hline $25-29$ years & $1 \cdot 5$ & $1 \cdot 0,2 \cdot 2$ & \\
\hline$\geq 30$ years & $1 \cdot 1$ & $0 \cdot 6,2 \cdot 0$ & \\
\hline \multicolumn{3}{|l|}{ Smoking during pregnancy } & 0.33 \\
\hline No & $1 \cdot 2$ & $0 \cdot 8,1 \cdot 9$ & \\
\hline Yes & $1 \cdot 0$ & Reference & \\
\hline \multicolumn{3}{|l|}{ Parity } & 0.04 \\
\hline 1 & $1 \cdot 7$ & $1 \cdot 0,2 \cdot 8$ & \\
\hline $2-3$ & $1 \cdot 2$ & $0 \cdot 8,2 \cdot 0$ & \\
\hline$\geq 4$ & $1 \cdot 0$ & Reference & \\
\hline \multicolumn{4}{|c|}{ Obstetric and neonatal complications } \\
\hline \multicolumn{3}{|c|}{ Pregnancy complications } & 0.82 \\
\hline No & $1 \cdot 0$ & Reference & \\
\hline Yes & $1 \cdot 0$ & $0.8,1 \cdot 2$ & \\
\hline \multicolumn{3}{|l|}{ Previous spontaneous abortion } & $<0.01$ \\
\hline No & $1 \cdot 0$ & Reference & \\
\hline Yes & $2 \cdot 2$ & $1 \cdot 8,2 \cdot 8$ & \\
\hline
\end{tabular}

main reason behind the relatively high rate of missing information on folic acid intake (30\%) is that, as mentioned earlier, data on folic acid were obtained through direct interview with mothers. Depending on the workload in the delivery suite and nursery, data collectors might drop the whole interview with the mother, including information on folic acid.

\section{Conclusion}

According to the results of the present study, Lebanon currently has a low rate of preconceptional folic acid supplement use. A national intervention programme emphasizing the importance of preconceptional folic acid use would be ideal in the Lebanese public health setting. Due to social and religious factors, nearly all pregnancies in Lebanon occur following wedlock, where obligatory premarital blood tests are done before a marriage certificate can be obtained. Awareness at this stage, possibly achieved through the distribution of brochures in medical laboratories, would be both a low-cost and efficient method of raising public knowledge. It is believed that such an intervention would be effective because the average length of time between marriage and first pregnancy was found to be 1.3 years, and hence information provided at the time of marriage could still be remembered.

\section{Acknowledgements}

The project was funded by the Bixby Program in Population Research at the University of California-Los Angeles School of Public Health.

Author contributions: H.T. had overall supervision of the project, design and write-up of the manuscript; G.H. contributed to the study concept, design and critical revision of the manuscript; M.A. participated in the literature review and write-up of study; G.M. undertook data management and statistical analyses; F.E.-K. contributed to study design and critical revision of the manuscript; M.S. contributed to study design and critical revision of the manuscript; K.Y. contributed to data acquisition and supervision of the project. The authors declare no conflict of interest.

\section{References}

1. World Bank (1993) World Development Report 1993: Investing in Health. New York: Oxford University Press.

2. Finnell RH, Shaw GM, Lammer EJ, Brandl KL, Carmichael SL \& Rosenquist TH (2004) Gene-nutrient interactions: importance of folates and retinoids during early embryogenesis. Toxicol Appl Pharmacol 198, 75-85.

3. Centers for Disease Control and Prevention (CDC) (2004) Use of vitamins containing folic acid among women of childbearing age - United States, 2004. MMWR Morb Mortal Wkly Rep 53, 847-850.

4. Berry RJ, Li Z, Erickson JD et al. (1999) Prevention of neural-tube defects with folic acid in China. China-US Collaborative Project for Neural Tube Defect Prevention. $N$ Engl J Med 341, 1485-1490.

5. Czeizal AE, Thoth M \& Rockenbauer M (1996) Populationbased case control study of folic acid supplementation during pregnancy. Teratology 53, 345-351.

6. Ray JG, Singh G \& Burrows RF (2004) Evidence for suboptimal use of periconceptional folic acid supplements globally. BJOG 111, 399-408. 
7. Ward M, Hutton J, McDonnell R, Bachir N, Scallan E, O'Leary M, Hoey J, Doyle A, Delany V \& Sayers G (2004) Folic acid supplements to prevent neural tube defects: trends in east of Ireland 1996-2002. Ir Med J 97, 274-276.

8. Bower C, Blum L, O’Daly K, Higgins C, Loutsky F \& Kosky C (1997) Promotion of folate for the prevention of neural tube defects: knowledge and use of periconceptional folic acid supplements in Western Australia, 1992 to 1995. Aust N Z J Public Health 21, 716-721.

9. Liu S, West R, Randell E, Longerich L, O'Connor KS, Scott H, Crowley M, Lam A, Prabhakaran V \& McCourt C (2004) A comprehensive evaluation of food fortification with folic acid for the primary prevention of neural tube defects. BMC Pregnancy Childbirth $\mathbf{4}, 20$.

10. Bower C \& Stanley FJ (2004) Case for mandatory fortification of food with folate in Australia, for the prevention of neural tube defects. Birth Defects Res A Clin Mol Teratol 70, 842-843.

11. Sichert-Hellert W \& Kersting M (2004) Fortifying food with folic acid improves folate intake in German infants, children, and adolescents. J Nutr 134, 2685-2690.

12. Hertrampf E \& Cortes F (2004) Folic acid fortification of wheat flour: Chile. Nutr Rev 62, S44-S48.

13. Chen LT \& Rivera MA (2004) The Costa Rican experience: reduction of neural tube defects following food fortification programs. Nutr Rev 62, S40-S43.

14. Mills JL \& Signore C (2004) Neural tube defect rates before and after food fortification with folic acid. Birth Defects Res A Clin Mol Teratol 70, 844-845.

15. Takimoto H, Mito N, Umegaki K, Ishiwaki A, Kusama K, Abe S, Yamawaki M, Fukuoka $\mathrm{H}$, Ohta C \& Yoshiike N (2007) Relationship between dietary folate intakes, maternal plasma total homocysteine and B-vitamins during pregnancy and fetal growth in Japan. Eur $J$ Nutr 46 , 300-306.

16. Järvenpää J, Schwab U, Lappalainen T, Päkkilä M, Niskanen L, Punnonen K \& Ryynänen M (2007) Fortified mineral water improves folate status and decreases plasma homocysteine concentration in pregnant women. J Perinat Med 35, 108-114.
17. Sen S, Manzoor A, Deviasumathy M \& Newton C (2001) Maternal knowledge, attitude and practice regarding folic acid intake during the periconceptional period. Public Health Nutr 4, 909-912.

18. Verkleij-Hagoort AC, de Vries JH, Ursem NT, de Jonge R, Hop WC \& Steegers-Theunissen RP (2006) Dietary intake of B-vitamins in mothers born a child with a congenital heart defect. Eur J Nutr 45, 478-486.

19. Amitai Y, Fisher N, Haringman M, Meiraz H, Baram N \& Leventhal A (2004) Increased awareness, knowledge and utilization of preconceptional folic acid in Israel following a national campaign. Prev Med 39, 731-737.

20. Abdulrazzaq YM, Al-Gazali LI, Bener A, Hossein M, Verghese M \& Dawodu A (2003) Folic acid awareness and intake survey in the United Arab Emirates. Reprod Toxicol 17, 171-176.

21. Republic of Lebanon Ministry of Public Health (1998) Maternal and Child Health Survey, Pan Arab Project for Child Development. Beirut: Ministry of Public Health.

22. van der Pal-de Bruin KM, de Walle HE, de Rover CM Jeeninga W, Cornel MC \& de Jong-van den Berg LT (2003) Influence of educational level on determinants of folic acid use. Paediatr Perinat Epidemiol 17, 256-263.

23. Nawapun K \& Phupong V (2007) Awareness of the benefits of folic acid and prevalence of the use of folic acid supplements to prevent neural tube defects among Thai women. Arch Gynecol Obstet 276, 53-57.

24. Santos LM \& Pereira MZ (2007) The effect of folic acid fortification on the reduction of neural tube defects. Cad Saude Publica 23, 17-24.

25. Eurocat (2005) NTD Rates and Survey of Folic Acid Policy and Practice in European Countries. http://www. eurocat.ulster.ac.uk/pubdata/Folic-Acid.html (accessed September 2006).

26. Cleves MA, Hobbs CA, Collins HB, Andrews N, Smith LN \& Robbins JM (2004) Folic acid use by women receiving routine gynecologic care. Obstet Gynecol 103, 746-753.

27. Scholl TO \& Johnson WG (2004) Folic acid: influence on the outcome of pregnancy. Am J Clin Nutr 71, 5 Suppl., 1295S-1303S. 